\title{
Atherosclerosis in aged mice over-expressing the reverse cholesterol transport genes
}

J.A. Berti ${ }^{1}$,

E.C. de Faria ${ }^{2}$ and H.C.F. Oliveira ${ }^{1}$
${ }^{1}$ Departamento de Fisiologia e Biofísica, Instituto de Biologia, and 2Departamento de Patologia Clínica, Faculdade de Ciências Médicas, Universidade Estadual de Campinas, Campinas, SP, Brasil

\author{
Correspondence \\ H.C.F. Oliveira \\ Departamento de Fisiologia e \\ Biofísica \\ Instituto de Biologia, UNICAMP \\ 13083-970 Campinas, SP \\ Brasil \\ Fax: +55-19-3788-6185 \\ E-mail: ho98@unicamp.br
}

Research supported by FAPESP, CNPq

and the PRONEX program of CNPq.

Part of a Doctoral thesis presented by J.A. Berti to the Departamento de Fisiologia e Biofísica, UNICAMP,

Campinas, SP, Brazil.

Received September 9, 2004

Accepted January 6, 2005

Abstract

We determined whether over-expression of one of the three genes involved in reverse cholesterol transport, apolipoprotein (apo) AI, lecithin-cholesterol acyl transferase (LCAT) and cholesteryl ester transfer protein (CETP), or of their combinations influenced the development of diet-induced atherosclerosis. Eight genotypic groups of mice were studied (AI, LCAT, CETP, LCAT/AI, CETP/AI, LCAT/ CETP, LCAT/AI/CETP, and non-transgenic) after four months on an atherogenic diet. The extent of atherosclerosis was assessed by morphometric analysis of lipid-stained areas in the aortic roots. The relative influence $\left(\mathrm{R}^{2}\right)$ of genotype, sex, total cholesterol, and its main sub-fraction levels on atherosclerotic lesion size was determined by multiple linear regression analysis. Whereas apo $\mathrm{AI}\left(\mathrm{R}^{2}=0.22, \mathrm{P}<\right.$ $0.001)$ and CETP $\left(R^{2}=0.13, P<0.01\right)$ expression reduced lesion size, the LCAT $\left(\mathrm{R}^{2}=0.16, \mathrm{P}<0.005\right)$ and LCAT/AI $\left(\mathrm{R}^{2}=0.13, \mathrm{P}<0.003\right)$ genotypes had the opposite effect. Logistic regression analysis revealed that the risk of developing atherosclerotic lesions greater than the 50th percentile was 4.3-fold lower for the apo AI transgenic mice than for non-transgenic mice, and was 3.0-fold lower for male than for female mice. These results show that apo AI overexpression decreased the risk of developing large atherosclerotic lesions but was not sufficient to reduce the atherogenic effect of LCAT when both transgenes were co-expressed. On the other hand, CETP expression was sufficient to eliminate the deleterious effect of LCAT and LCAT/AI overexpression. Therefore, increasing each step of the reverse cholesterol transport per se does not necessarily imply protection against atherosclerosis while CETP expression can change specific atherogenic scenarios.

\section{Introduction}

Numerous epidemiological studies have demonstrated an inverse relationship between HDL-cholesterol and coronary heart disease $(1,2)$. A meta-analysis of clinical trials data and other studies has revealed that an in-
Key words

- Apolipoprotein Al

- Cholesteryl ester transfer protein

- Lecithin-cholesterol

acyl transferase

- Atherosclerosis

- Transgenic mice crease of $1 \mathrm{mg} / \mathrm{dl}$ in HDL-cholesterol was accompanied by a 2 and 3\% reduction in cardiovascular risk in men and women, respectively (1). However, high levels of HDL-cholesterol are not always protective 
$(3,4)$, and patients with low HDL-cholesterol levels do not necessarily show premature atherosclerosis (5). Thus, the HDL-cholesterol turnover rate rather than its steadystate plasma concentration seems to be more relevant for protection against atherosclerosis.

Proteins involved in reverse cholesterol transport (RCT) can markedly modify the turnover rate of HDL-cholesterol and the development of atherosclerosis. RCT is an efficient mechanism for removing excess cholesterol from tissues to the liver for excretion. This system involves an efflux of free cholesterol from cell membranes via ATP binding cassette transporter (ABCA1) (6) and scavenger receptor type B class 1 (SR-B1) (7) to lipid-poor apolipoprotein (apo) AI. This apo is partly derived from the gut and liver and partly from the intravascular lipolysis of triglyceride-rich lipoproteins. The subsequent steps of RCT include cholesterol esterification by lecithin-cholesterol acyl transferase (LCAT) (8) and the transfer of cholesteryl ester to triglyceride-rich lipoproteins by cholesteryl ester transfer protein (CETP) (9). Lastly, cholesteryl ester can be transferred to the liver directly from HDL through SR-B1 receptors (7) and indirectly from apo B-containing lipoproteins through LDL receptors (10) and LDL receptor-related proteins (11). The action of CETP on HDL facilitates the LCAT reaction rate (12) and hence the cell cholesterol efflux rate. Also, the combined action of CETP and hepatic lipase on mature $\mathrm{HDL}_{2}$ regenerates $\mathrm{HDL}_{3}$ and pre-beta HDL, sub-fractions that are better acceptors for cell cholesterol (9).

Plasma HDL levels are modulated by several environmental and genetic factors. Genetic studies on different populations have suggested that the contribution of the genetic component to variation in HDL levels is large but varies widely: 44 (13), 65 (14), and $83 \%$ (15). Experimental investigation of the genetic determinants of HDL levels and atherosclerosis has been greatly facilitated by models of genetically modified mice. The overexpression of apo AI in transgenic mice attenuated atherogenesis in the wild-type background and in atherosclerosis-susceptible strains such as apo E knockout mice $(16,17)$. Separate overexpression of LCAT (18) or CETP (19) aggravated atherogenesis whereas, in combination, CETP and LCAT expression in double-transgenic mice reduced the severity of atherosclerosis seen in LCAT single-transgenic mice (18).

The aim of this study was to investigate whether the separate or combined overexpression of apo AI, LCAT and CETP influences the development of diet-induced atherosclerosis in aged mice.

\section{Material and Methods}

\section{Animal protocols}

The animal protocols were approved by the Ethics Committee in Animal Experimentation of the Institution (CEEA/UNICAMP) and followed the Principles of Laboratory Animal Care (NIH publication No. 85-23, revised 1985). The parental mice expressing human apo AI, LCAT and CETP transgenes have been described elsewhere (20-22) and were derived from colonies maintained by Dr. A.R. Tall (Columbia University, New York, NY, USA). Two rounds of mating were necessary to generate the eight genotypes of mice used: LCAT, AI, CETP, LCAT/ AI, LCAT/CETP, AI/CETP, LCAT/AI/CETP transgenic and non-transgenic mice. The genotypic screening was done as previously described (20-22), but only at the end of the study. All generated male and female mice aged $18 \pm 2$ months $(\mathrm{N}=95)$ were placed on an atherogenic high fat, high cholesterol diet containing $20 \%$ fat, $1.25 \%$ cholesterol, and $0.5 \%$ cholic acid (Cat. \#611208; Dyets, Inc., Bethlehem, PA, USA) for 16 weeks. After this period, the mice were anesthetized with ketamine $(50 \mathrm{mg} / \mathrm{kg}$, ip, Ketalar; Parke-Davis, São Paulo, SP, Brazil) and xylazine (10 mg/ 
kg, ip, Rompum; Bayer S.A., São Paulo, SP, Brazil), and blood samples were drawn from the retro-orbital plexus into heparinized hematocrit tubes before perfusing and excising the hearts. Eighteen mice (19\%) died during the diet period, probably because of liver disease since, at the end of the study, all mice showed signals of hepatic steatosis and had gallbladders full of gallstones. Five mice were excluded from the study because of technical problems during the histological processing of the heart and one was excluded because of inconclusive genotyping. The plasma levels of triacylglycerol and total cholesterol were determined by enzymatic methods according to manufacturer instructions (Roche Diagnostics GmbH, Indianapolis, IN, USA). HDL-cholesterol was determined by the homogeneous assay (PEGME method) using an automated system (Hitachi 917; Roche).

\section{Histological analysis of atherosclerotic lesions}

The hearts of anesthetized mice were perfused in situ with phosphate-buffered saline (PBS) followed by 10\% PBS-buffered formaldehyde, and then excised and fixed in $10 \%$ formaldehyde for at least two days. The hearts were then embedded sequentially in 5,10 , and $25 \%$ gelatin. Processing and staining were done according to Paigen et al. (23). The lipid-stained lesions were quantified as described by Rubin et al. (16) using Image Pro Plus software (version 3.0) for image analysis (Media Cybernetics, Silver Spring, MD, USA). The slides were read before genotype identification. The areas of the lesions were expressed as the sum of the lesions in six $10 \mu \mathrm{m}$-sections, $80 \mu \mathrm{m}$ apart along $480 \mu \mathrm{m}$ of aorta. Because several other studies have revealed a predilection for the development of lesions in the aortic root, the segment chosen for analysis extended from beyond the aortic sinus up to the point where the aorta first becomes rounded (16).

\section{Statistical analysis}

Data are reported as means \pm SEM and were analyzed by the Kruskal-Wallis test for multiple comparisons and the Mann-Whitney test for two-group comparisons. The Spearman test was used to correlate the variables with the lesion size. Hierarchical, multiple linear regression analysis was used to assess the influence of specific genotypes, sex, plasma triglycerides, total cholesterol, and HDL-cholesterol concentrations (independent variables) on the size of the atherosclerotic lesion (dependent variable). These results are reported as coefficient of determination $\left(\mathrm{R}^{2}\right)$, which indicates the percentage of variation in the dependent variable that can be explained by the independent variables. Multiple logistic regression analysis was used to assess the risk of developing atherosclerotic lesions larger than the 50th percentile (median). The level of significance was established as $\mathrm{P} \leq 0.05$ and data were considered to be marginally significant at $0.05<\mathrm{P}<0.10$. All statistical analyses were done using the SAS statistical software package (version 8).

\section{Results}

Table 1 shows the plasma lipid and HDLcholesterol concentrations of the eight genotypic groups expressing apo AI, CETP and LCAT or their combinations. None of the mice developed hypercholesterolemia after 4 months on the high fat, high cholesterol, cholate-containing diet. Indeed, the plasma cholesterol levels of wild-type C57B16 mice fed this same diet for 120 days did not exceed $200 \mathrm{mg} / \mathrm{dl}$ (24). Multiple comparisons by the Kruskal-Wallis test showed no major differences in the total cholesterol, triglyceride and HDL-cholesterol levels of the groups, or in the total cholesterol/HDL and HDL/ non-HDL-cholesterol ratios. Thus, the expected phenotypes of increased HDL levels in mice overexpressing apo AI and LCAT 
and decreased HDL levels in mice expressing CETP were not observed after 4 months on the atherogenic diet. Previous studies (25-27) have shown that the HDL-lowering effect of CETP expression is not observed after treatment with this atherogenic diet or in endogenous hypercholesterolemia resulting from LDL receptor gene knockout.

The severity of the diet-induced atherosclerosis was assessed by morphometric analysis of the lipid-stained areas in the aortic roots (Figure 1). The average size of the atherosclerotic lesions in AI mice was threefold smaller than in CETP/AI and LCAT/AI mice, and four-fold smaller than in LCAT mice. Despite these striking differences, con- ventional nonparametric analysis of variance detected no significant effect of the eight distinct genotypes on the atherosclerotic lesion size. However, using pairwise comparisons, the lesion size in apo AI mice was significantly smaller than in CETP/AI $(\mathrm{P}=0.05)$ and LCAT/AI $(\mathrm{P}=0.02)$ mice and marginally significantly smaller than in LCAT mice $(\mathrm{P}=0.09)$.

Univariate correlation analysis of combined groups (Table 2) showed that lesion size correlated positively with total cholesterol, HDL and non-HDL levels, and with the total cholesterol/HDL ratio, and negatively with the HDL/non-HDL ratio. When each group was tested separately, lesion size

Table 1. Plasma lipid and lipoprotein concentrations in mice expressing combinations of apo Al, LCAT and CETP transgenes after 4 months on a high fat, high cholesterol cholate-containing diet.

\begin{tabular}{lrlllcll}
\hline Groups & N & \multicolumn{1}{c}{ TG } & Chol & HDL-Chol & non-HDL-Chol & Chol/HDL & HDL/non-HDL \\
\hline Non-Tg & 12 & $59 \pm 8$ & $124 \pm 18$ & $76 \pm 5$ & $48 \pm 11$ & $1.6 \pm 0.07$ & $2.0 \pm 0.28$ \\
CETP & 10 & $53 \pm 6$ & $126 \pm 9$ & $80 \pm 4$ & $46 \pm 5$ & $1.6 \pm 0.05$ & $1.9 \pm 0.17$ \\
LCAT & 5 & $70 \pm 11$ & $147 \pm 37$ & $89 \pm 18$ & $58 \pm 19$ & $1.6 \pm 0.07$ & $1.8 \pm 0.21$ \\
Al & 12 & $68 \pm 6$ & $132 \pm 10$ & $84 \pm 6$ & $43 \pm 4$ & $1.5 \pm 0.03$ & $2.0 \pm 0.13$ \\
CETP/LCAT & 7 & $54 \pm 5$ & $107 \pm 11$ & $72 \pm 6$ & $37 \pm 6$ & $1.5 \pm 0.05$ & $2.1 \pm 0.34$ \\
CETP/Al & 15 & $59 \pm 4$ & $128 \pm 12$ & $75 \pm 6$ & $53 \pm 6$ & $1.7 \pm 0.06$ & $1.6 \pm 0.19$ \\
LCAT/AI & 8 & $49 \pm 4$ & $128 \pm 24$ & $69 \pm 5$ & $66 \pm 28$ & $2.0 \pm 0.06$ & $1.7 \pm 0.35$ \\
CETP/LCAT/AI & 7 & $58 \pm 5$ & $159 \pm 17$ & $85 \pm 4$ & $61 \pm 10$ & $1.7 \pm 0.12$ & $1.6 \pm 0.32$
\end{tabular}

Data are reported as means \pm SEM $(\mathrm{mg} / \mathrm{dl})$. Apo $\mathrm{Al}=$ apolipoprotein $\mathrm{Al}$; LCAT = lecithin-cholesterol acyl transferase; $\mathrm{CETP}=$ cholesteryl ester transfer protein; Non-Tg = non-transgenic; $\mathrm{TG}=$ triglycerides; $\mathrm{Chol}=$ cholesterol.

Figure 1. Area of aortic atherosclerotic lesions in aged CETP, apo $\mathrm{Al}$ and LCAT single- and multiple-transgenic and nontransgenic mice after 16 weeks on a high fat, high cholesterol, cholate-containing diet. The columns represent the mean \pm SEM of the number of mice indicated below the abscissa (in parentheses). Apo Al = apolipoprotein $\mathrm{Al}$; LCAT = lecithin-cholesterol acyl transferase; CETP = cholesteryl ester transfer protein; non- $\mathrm{Tg}=$ non-transgenic. ${ }^{*} \mathrm{P}=0.02$ between apo $\mathrm{Al}$ and LCAT/AI mice, $P=0.05$ between apo $\mathrm{Al}$ and CETP/Al, and $\mathrm{P}=$ 0.09 between apo Al and LCAT (Mann-Whitney test).

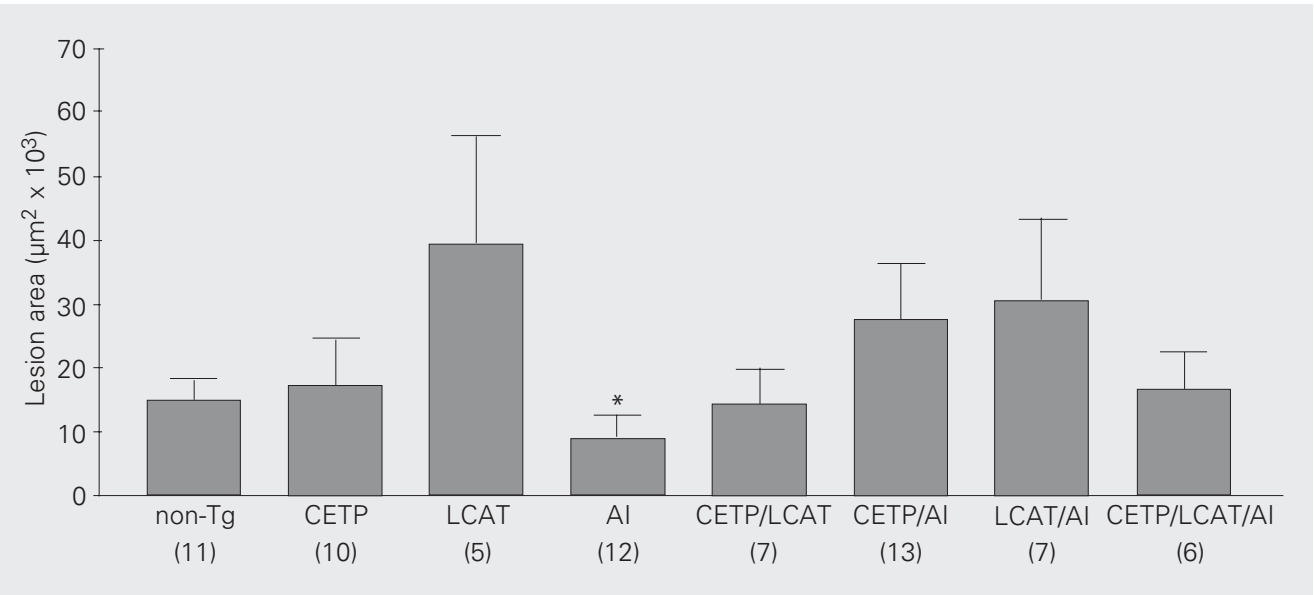


was positively correlated with total cholesterol, non-HDL-cholesterol and HDL-cholesterol levels in LCAT transgenic mice, indicating that HDL was not protective in these mice. In LCAT/AI mice, lesion size was inversely correlated with HDL-cholesterol levels, showing that apo AI expression in LCAT mice markedly changed the association between lesion size and HDL-cholesterol.

Hierarchical multiple regression analyses (Table 3) showed that the independent variables: cholesterol, HDL, non-HDL, HDL/ non-HDL, triglycerides, genotypes or transgenes, and sex, could explain part of the variation in the size of the atherosclerotic lesion (dependent variable) with 97-99.9\% confidence. Model I predicted that, regardless of the genotypes, total cholesterol and HDL-cholesterol together explain $11 \%$ of the variation in lesion size. The relationships that included specific genotypes with the power to influence lesion size are shown in models II to VI. The expression of apo AI (model V) and CETP (model VI) reduced lesion size, whereas the expression of LCAT (model IV) and LCAT/AI (models II and III) had the opposite effect. Male mice had smaller lesions (models II, IV, V, and VI), as previously reported (28).

Table 2. Univariate correlations between the atherosclerotic lesion area and the plasma total and lipoprotein cholesterol levels.

\begin{tabular}{lrccccc}
\hline Groups & N & Chol & HDL-Chol & non-HDL-Chol & Chol/HDL & HDL/non-HDL \\
\hline All & 71 & $0.40(0.0006)$ & $0.26(0.003)$ & $0.45(0.0001)$ & $0.38(0.002)$ & $-0.29(0.018)$ \\
LCAT & 5 & $0.93(0.02)$ & $0.92(0.03)$ & $0.94(0.02)$ & NS & NS \\
LCAT/Al & 7 & NS & $-0.79(0.058)$ & NS & NS & NS
\end{tabular}

Data are reported as Spearman correlation coefficients $(r)$ with $P$ values in parentheses. LCAT = lecithincholesterol acyl transferase; apo $\mathrm{Al}=$ apolipoprotein $\mathrm{Al}$; $\mathrm{Chol}=$ cholesterol; $\mathrm{NS}$ = nonsignificant.

Table 3. Influence (coefficient of determination, $\mathrm{R}^{2}$ ) of plasma lipids, lipoproteins, genotypes, and sex on the atherosclerotic lesion area in mice expressing combinations of apo Al, LCAT and CETP transgenes.

\begin{tabular}{|c|c|c|c|}
\hline Multiple linear regression models & Significant variables & $P$ value & Cumulative $\mathrm{R}^{2}$ \\
\hline $\begin{array}{l}\text { I. Regardless of the genotypes } \\
\text { log (lesion area) }=2.4+\log (\text { Chol) }-2.68 \log (H D L)\end{array}$ & $\begin{array}{l}\text { Chol } \\
\text { HDL-Chol }\end{array}$ & 0.03 & 0.11 \\
\hline $\begin{array}{l}\text { II. Each genotype vs non- } \mathrm{Tg} \\
\text { Lesion area }=22.2+18.0 \text { LCAT/AI }-13.6 \text { sex }\end{array}$ & $\begin{array}{l}\text { LCAT/Al genotype } \\
\text { sex (male) }\end{array}$ & 0.003 & 0.13 \\
\hline $\begin{array}{l}\text { III. Each genotype vs non-Tg } \\
\text { Lesion area }=29.0+16.7 \text { LCAT/Al }-6.9 \mathrm{HDL} / \text { non-HDL }\end{array}$ & $\begin{array}{l}\text { LCAT/Al genotype } \\
\text { HDL/non-HDL }\end{array}$ & 0.02 & 0.12 \\
\hline $\begin{array}{l}\text { IV. Presence vs absence of LCAT transgene } \\
\text { log (lesion area) }=2.7+0.45 \text { LCAT }-0.85 \text { sex }\end{array}$ & $\begin{array}{l}\text { LCAT transgene } \\
\text { sex (male) }\end{array}$ & 0.005 & 0.16 \\
\hline $\begin{array}{l}\text { V. Presence vs absence of } \mathrm{Al} \text { transgene } \\
\text { Lesion area }=2.14-1.89 \mathrm{Al}+0.20 \mathrm{Chol}-13.77 \text { sex }\end{array}$ & $\begin{array}{l}\text { apo Al transgene } \\
\text { Chol, sex (male) }\end{array}$ & 0.0006 & 0.22 \\
\hline $\begin{array}{l}\text { VI. Presence vs absence of CETP transgene } \\
\text { log (lesion area) }=2.99-0.18 \text { CETP }-0.84 \text { sex }\end{array}$ & $\begin{array}{l}\text { CETP transgene } \\
\text { sex (male) }\end{array}$ & 0.01 & 0.13 \\
\hline
\end{tabular}

Independent variables: total cholesterol (Chol), HDL-Chol, non-HDL-Chol, HDL/non-HDL, triglycerides, genotypes or transgenes, and sex (male/female). apo Al = apolipoprotein Al; LCAT = lecithin-cholesterol acyl transferase; CETP = cholesteryl ester transfer protein; non- $\mathrm{Tg}=$ non-transgenic. 
The quantitative interpretation of these models is as follows:

Model I. Regardless of the genotypes, a $1 \%$ elevation in cholesterol levels increases the lesion size by $2.4 \%$ when HDL levels are maintained, and a $1 \%$ increase in HDL levels decreases the lesion size by $2.7 \%$ when cholesterol levels are maintained.

Model II. The LCAT/AI genotype increases the lesion size by 18,000 units as compared to non-transgenic animals of each gender. The lesion size is about 14,000 units smaller in males than in females in a given genotype.

Model III. For the same HDL/non-HDL ratio, the LCAT/AI genotype increases the lesion size by about 17,000 units relative to non-transgenic animals. An increase of 1 unit in the HDL/non-HDL ratio decreases the lesion size by about 7000 units in a given genotype.

Model $I V$. For the same sex, the LCAT expression increases the lesion size by $56.8 \%$ compared to all mice not expressing LCAT. For a given genotype, male mice show a $57.3 \%$ decrease in lesion size.

Model $V$. For a given sex with the same cholesterol levels, apo AI expression reduces lesion size by about 1900 units compared to all mice that did not express apo AI. For a given genotype, an increase of $1 \mathrm{mg} / \mathrm{dl}$ in the cholesterol concentration increases lesion size by 200 units and male sex decreases lesion size by 14,000 units.

Model VI. For the same sex, CETP expression decreases lesion size by $16.5 \%$ com-

Table 4. Odds ratio (OR) and 95\% confidence interval $(\mathrm{Cl})$ relating the prevalence of an atherosclerotic lesion greater than the 50th percentile and specific genotypes in mice expressing combinations of apolipoprotein (apo) Al, lecithin-cholesterol acyl transferase, and cholesteryl ester transfer protein.

\begin{tabular}{lcccr}
\hline Effect & Point estimate & $95 \% \mathrm{Cl}$ & P value & OR \\
\hline Sex (male) & 0.329 & $0.12-0.90$ & 0.029 & -3.04 \\
Apo Al genotype & 0.232 & $0.05-1.00$ & 0.050 & -4.31 \\
\hline
\end{tabular}

Multiple logistic regression covariates: cholesterol (Chol), triglycerides, HDL, HDL/ non-HDL, Chol/HDL. pared to all mice not expressing CETP, and male sex decreases the size of lesions by $57 \%$ in a given genotype.

Logistic regression analysis (Table 4) revealed that the risk of developing atherosclerotic lesions larger than the median value was 4.3-fold lower for apo AI transgenic mice than for non-transgenic mice, and 3.0fold lower for male than for female mice.

\section{Discussion}

Multiple linear regression models showed that cholesterol, HDL-cholesterol, sex and the expression of RCT genes explained 11$22 \%$ of the variation in the size of the dietinduced atherosclerotic lesions in transgenic mice. Since the environment, age, weight, and diet did not vary among groups, the rest of the variation in lesion size must be explained by other genetic factors not controlled in this study. Interactions between the transgenes studied and other genes that potentially modify the susceptibility to atherosclerosis were not investigated. Recently, Stein et al. (29) provided evidence of a putative genetic basis for resistance to atherosclerosis. The proposed mechanism would involve genes controlling lipoprotein metabolism such as the $\mathrm{ABC}$ gene family, apo $\mathrm{E}$, class $\mathrm{A}$ and $\mathrm{B}$ scavenger receptors, as well as inflammatory and oxidative stress-responsive genes.

Some of the associations found here were expected, such as the negative impact of total cholesterol concentrations and the protective effects of HDL-cholesterol and HDL/ non-HDL ratios on the severity of the disease (uni- and multivariate analyses; Tables 2 and 3). The atheroprotective role of HDL has been well documented in animal (16, $17,30)$ and human $(1,2)$ studies. Although the mice studied here did not present a lipemic phenotype, the interplay of the plasma concentrations of apo AI, LCAT and CETP partly explained the extent of the diet-induced atherosclerotic lesions. The strongest 
genetic effect was detected in the LCAT/AI genotype, which, in the absence of CETP, worsened atherosclerosis when compared to non-transgenic mice (Table 3, models II and III). The CETP genotype per se had a weak effect, but sufficient to eliminate the deleterious effect of the LCAT and LCAT/AI genotypes since the co-expression of CETP/LCAT and CETP/LCAT/AI prevented the increase in their lesion size. The expression of apo AI alone had a beneficial effect, as seen in paired comparisons (Figure 1) and by multivariate analysis (Table 3 , model $\mathrm{V}$ ). This beneficial role was confirmed by logistic regression analysis, which indicated a lower risk of developing larger lesion sizes (above the 50th percentile) in the AI group when compared to non-transgenic mice. Surprisingly, the expression of apo AI was insufficient to improve the atherogenic effect of LCAT when both transgenes were co-expressed. The reason for this may be related to an increased cholesterol esterification rate in HDL in the absence of an efficient mechanism for cholesteryl ester removal. This would lower the hepatic cholesteryl ester uptake and the rate of regeneration of HDL subfractions that are good cell cholesterol acceptors. Indeed, Collet et al. (22) showed that the fractional catabolic rate of HDLcholesteryl ester in LCAT/AI mice was markedly lower than in AI, AI/CETP and LCAT/ $\mathrm{AI} / \mathrm{CETP}$ mice, thus supporting the idea that
CETP expression in LCAT/AI mice has an anti-atherogenic role by increasing the rate of HDL-cholesteryl ester removal from plasma. The harmful effect of LCAT overexpression and its correction by CETP expression have also been described by Foger et al. (18). However, the atherogenic effect of LCAT/AI expression was unsuspected and neutralization of this harmful effect by CETP expression is now demonstrated for the LCAT/AI background.

In a study of the effects of up-regulating individual steps of the RCT ( $7 \alpha$ hydroxylase, SR-BI, LCAT, and apo AI), Alam et al. (31) showed that the cholesterol flux through the entire RCT pathway was not increased. Thus, increasing each step per se does not necessarily guarantee protection against atherosclerosis. We showed here that the expression of LCAT and LCAT/AI resulted in a higher risk of developing atherosclerosis, while the expression of CETP in these backgrounds neutralized this atherogenic scenario, and that apo AI overexpression reduced the risk of developing large size atherosclerotic lesions.

\section{Acknowledgments}

The authors wish to thank Samara Flamini Kiihl for the statistical analyses and Stephen Hyslop for English revision.

\section{References}

1. Gordon DJ, Probstfield JL, Garrison RJ, Neaton JD, Castelli WP, Knoke JD, Jacobs Jr DR, Bangdiwala S \& Tyroler HA (1989). Highdensity lipoprotein cholesterol and cardiovascular disease. Four prospective American studies. Circulation, 79: 8-15.

2. Zambon A \& Hokanson JE (1998). Lipoprotein classes and coronary disease regression. Current Opinion in Lipidology, 9: 329-336.

3. Hirano K, Yamashita S, Kuga Y et al. (1995). Atherosclerotic disease in marked hyperalphalipoproteinemia. Combined reduction of cholesteryl ester transfer protein and hepatic triglyceride lipase. Arteriosclerosis, Thrombosis and Vascular Biology, 15: 1849-1856.

4. Zhong S, Sharp DS, Grove JS, Bruce C, Yano K, Curb JD \& Tall AR (1996). Increased coronary heart disease in Japanese-American men with mutation in the cholesteryl ester transfer protein gene despite increased HDL levels. Journal of Clinical Investigation, 97: 2917-2923

5. Breslow JL (1995). Familial disorders of high-density lipoprotein metabolism. In: Scriver CR \& Beaudet AL (Editors), The Metabolic Basis of Inherited Disease. McGraw-Hill, New York, 2031-2052.

6. Oram JF, Lawn RM, Garvin MR \& Wade DP (2000). ABCA1 is the CAMP-inducible apolipoprotein receptor that mediates cholesterol secretion from macrophages. Journal of Biological Chemistry, 275: 34508-34511.

7. Rigotti AMH \& Krieger M (2003). The role of the high-density lipoprotein receptor SR-BI in the lipid metabolism of endocrine and other tissues. Endocrine Reviews, 24: 357-387.

8. Glomset JA (1968). The plasma lecithins:cholesterol acyltransferase 
reaction. Journal of Lipid Research, 9: 155-167.

9. Tall AR, Jiang X, Luo Y \& Silver D (2000). 1999 George Lyman Duff memorial lecture: lipid transfer proteins, HDL metabolism, and atherogenesis. Arteriosclerosis, Thrombosis and Vascular Biology, 20: 1185-1188.

10. Brown MS \& Goldstein JL (1986). A receptor-mediated pathway for cholesterol homeostasis. Science, 232: 34-47.

11. Herz J, Hamann U, Rogne S, Myklebost O, Gausepohl H \& Stanley KK (1988). Surface location and high affinity for calcium of a 500-kD liver membrane protein closely related to the LDL-receptor suggest a physiological role as lipoprotein receptor. EMBO Journal, 7: 41194127.

12. Oliveira HC, Ma L, Milne R, Marcovina SM, Inazu A, Mabuchi H \& Tall AR (1997). Cholesteryl ester transfer protein activity enhances plasma cholesteryl ester formation. Studies in CETP transgenic mice and human genetic CETP deficiency. Arteriosclerosis, Thrombosis and Vascular Biology, 17: 1045-1052.

13. Heller DA, de Faire U, Pedersen NL, Dahlen G \& McClearn GE (1993). Genetic and environmental influences on serum lipid levels in twins. New England Journal of Medicine, 328: 1150-1156.

14. Steinmetz J, Boerwinkle E, Gueguen R, Visvikis S, Henny J \& Siest $G$ (1992). Multivariate genetic analysis of high density lipoprotein particles. Atherosclerosis, 92: 219-227.

15. Perusse L, Rice T, Despres JP et al. (1997). Familial resemblance of plasma lipids, lipoproteins and postheparin lipoprotein and hepatic lipases in the HERITAGE Family Study. Arteriosclerosis, Thrombosis and Vascular Biology, 17: 3263-3269.

16. Rubin EM, Krauss RM, Spangler EA, Verstuyft JG \& Clift SM (1991). Inhibition of early atherogenesis in transgenic mice by human apolipoprotein Al. Nature, 353: 265-267.

17. Paszty C, Maeda N, Verstuyft J \& Rubin EM (1994). Apolipoprotein Al transgene corrects apolipoprotein E deficiency-induced atherosclerosis in mice. Journal of Clinical Investigation, 94: 899-903.

18. Foger B, Chase M, Amar MJ et al. (1999). Cholesteryl ester transfer protein corrects dysfunctional high density lipoproteins and reduces aortic atherosclerosis in lecithin cholesterol acyltransferase transgenic mice. Journal of Biological Chemistry, 274: 36912-36920.

19. Marotti KR, Castle CK, Boyle TP, Lin AH, Murray RW \& Melchior GW (1993). Severe atherosclerosis in transgenic mice expressing simian cholesteryl ester transfer protein. Nature, 364: 73-75.

20. Jiang XC, Agellon LB, Walsh A, Breslow JL \& Tall A (1992). Dietary cholesterol increases transcription of the human cholesteryl ester transfer protein gene in transgenic mice. Dependence on natural flanking sequences. Journal of Clinical Investigation, 90: 1290-1295.

21. Francone OL, Gong EL, Ng DS, Fielding CJ \& Rubin EM (1995). Expression of human lecithin-cholesterol acyltransferase in transgenic mice. Effect of human apolipoprotein Al and human apolipoprotein All on plasma lipoprotein cholesterol metabolism. Journal of Clinical Investigation, 96: 1440-1448.

22. Collet $X$, Tall AR, Serajuddin H, Guendouzi K, Royer L, Oliveira H, Barbaras R, Jiang XC \& Francone OL (1999). Remodeling of HDL by CETP in vivo and by CETP and hepatic lipase in vitro results in enhanced uptake of HDL CE by cells expressing scavenger receptor B-I. Journal of Lipid Research, 40: 1185-1193.

23. Paigen B, Morrow A, Holmes PA, Mitchell D \& Williams RA (1987). Quantitative assessment of atherosclerotic lesions in mice. Atherosclerosis, 68: 231-240

24. Johnston TP, Baker JC, Hall D, Jamal S, Palmer WK \& Emeson EE (2000). Regression of poloxamer 407-induced atherosclerotic lesions in C57BL/6 mice using atorvastatin. Atherosclerosis, 149: 303-313.

25. Cazita PM, Berti JA, Aoki C, Gidlund M, Harada LM, Nunes VS, Quintao EC \& Oliveira HC (2003). Cholesteryl ester transfer protein expression attenuates atherosclerosis in ovariectomized mice. Journal of Lipid Research, 44: 33-40.

26. Takahashi H, Takahashi A, Maki M, Sasai H \& Kamada M (2001). Effect of CETP on the plasma lipoprotein profile in four strains of transgenic mouse. Biochemical and Biophysical Research Communications, 283: 118-123.

27. Plump AS, Masucci-Magoulas L, Bruce C, Bisgaier CL, Breslow JL \& Tall AR (1999). Increased atherosclerosis in ApoE and LDL receptor gene knock-out mice as a result of human cholesteryl ester transfer protein transgene expression. Arteriosclerosis, Thrombosis and Vascular Biology, 19: 1105-1110.

28. Paigen B, Holmes PA, Mitchell D \& Albee D (1987). Comparison of atherosclerotic lesions and HDL-lipid levels in male, female, and testosterone-treated female mice from strains C57BL/6, BALB/c, and $\mathrm{C} 3 \mathrm{H}$. Atherosclerosis, 64: 215-221.

29. Stein O, Thiery J \& Stein $Y$ (2002). Is there a genetic basis for resistance to atherosclerosis? Atherosclerosis, 160: 1-10.

30. Stein O \& Stein $Y$ (1999). Atheroprotective mechanisms of HDL. Atherosclerosis, 144: 285-301.

31. Alam K, Meidell RS \& Spady DK (2001). Effect of up-regulating individual steps in the reverse cholesterol transport pathway on reverse cholesterol transport in normolipidemic mice. Journal of Biological Chemistry, 276: 15641-15649. 